\title{
Virtual Trial
}

\author{
Kamal Khatri \\ Computer Engineering Department \\ Institute of Technology and Management Universe \\ (ITMUTC), Jarod \\ Gujarat Technical University, Ahmedabad
}

\author{
Himani Modi \\ Computer Engineering Department \\ Institute of Technology and Management Universe \\ (ITMUTC), Jarod \\ Gujarat Technical University, Ahmedabad
}

\begin{abstract}
This paper present a Virtual mirror technique using in websites to try garments before customer buy. The technique helps the customer to check the product how it will look like once they choose to buy them. It's kind of unique concept in which customer gets the virtual experience before buying goods like readymade apparels. They search many websites which offers online buying of products but can't reflect the actual things. The customer may return goods if didn't suits $\mathrm{him} / \mathrm{her}$. To resolve this issue this paper proposed this mirror concept which facilitates try \& buy feature to customer. To create this functionality they have decided to use client side script code which combines product images \& give the virtualization of apparels. We can apply JavaScript code for developing entire concept. The image overlapping is used to create Virtualization. For this dummy image is used for men/women \& product image is overlapped on it using coordinates \& user will get virtualization of product.
\end{abstract}

\section{Keywords}

Virtual Trial, Augmented Reality, Virtual Mirror,Web-Portal.

\section{INTRODUCTION}

In today's world E-commerce web portal are driving the shopping industry in more rapidly form. Nowadays Online shopping is more preferable \& more convenient. It also helps people to avoid many problems involved in travelling to multistory mall or busy market. People love to find new arrivals for themselves. This papers shows how to implement the E-commerce web portal with virtualization concept. The project offers various categories of readymade garments with various products. People can search them based on categories. People can also view the product detail like product image, price, description etc. People can choose from products and use TRY - ON facility for upper body like Tops, T-shirts, shirts etc. to check whether the product is suits them or not. Once they check this they get the idea to buy this product or not, User project contains the facility of buying multiple product via cart facility. User can also make online payment / COD (Cash On Delivery) for the order transaction. We will use free payment gateway for making online payment like pay pal etc.The proposed web portal has 3 different interfaces Admin, Customer, Visitor.Admin can manage and control all data \& users. He is the supper user of web portal. Customer can buy new products using TRY ON facility, check order history, post feedback etc. Visitor can only view the products $\&$ check feedback.

\section{EXISTING SYSTEM}

\subsection{Existing E-Commerce Inventory}

In recent times there are so many E-commerce garment website available for online shopping. Customer can able to purchase cloths using this website, but sometimes they have to suffer from certain issues such as size problems, colour problem and many more. So, customer dissatisfied to buy that product, after facing such problems. Due to the growing interest in Augmented Reality, the idea of virtual clothes is not new [2][3]. Most of the early applications attempted to do this by overlaying a static image of clothing over an image of the user captured by a camera or any digital camera. But, like any other idea, the virtual trial room involved from very basic solutions to more advanced solutions which were more in sync with actual reality. This is in fact, the basic motivation behind any Augmented Reality application.

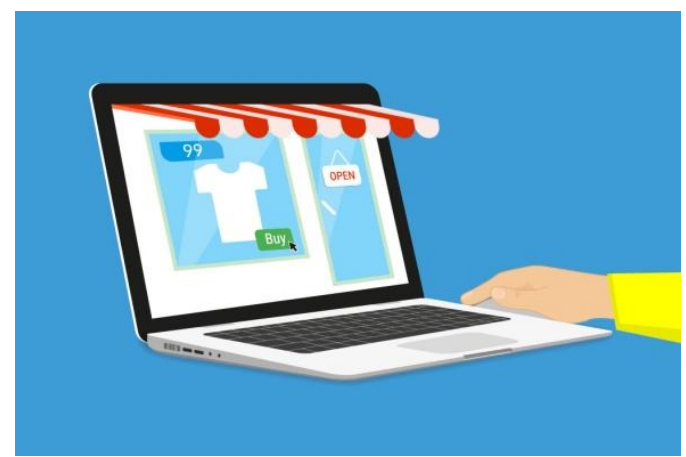

Fig 1: User Buying Cloths from Website

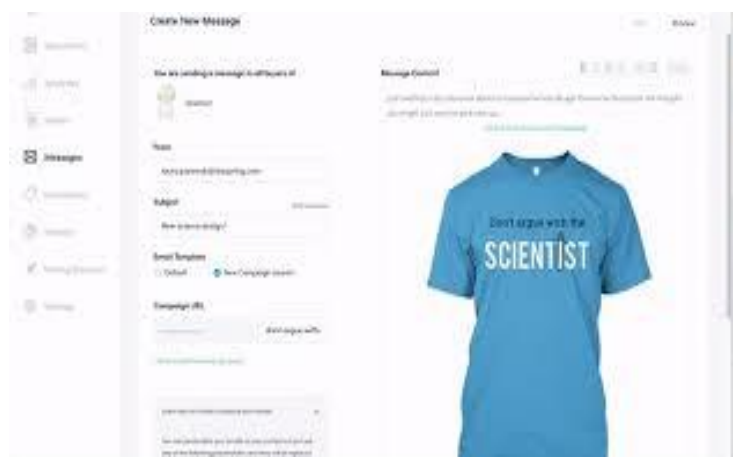

Fig 2: Different Cloth

\subsection{Existing System for Purchasing} Garments

A lot of shoppers have encountered many problems while shopping at a high-end place for readymade garments, especially during peak hours, such as weekends. Tiresome lines, numerous restrictions, enormous crowds make it quite an unpleasant experience. Huge number of customers, and minimum numbers of trial rooms results in quite a lot of waiting time for customers, ultimately resulting in dissatisfaction. Due to security reasons, there is also a restriction on the number of garments that can be taken at one instance of time for trial. It increases the overall shopping time due to multiple trips from the shelves to the trial rooms. 
From the boutique's point of view, a large percentage of thefts happen because of sneaking in garments while in the trial room. Also they are unable to show the customers the fresh stock that is supposed to be delivered to the shop in the coming few days. To overcome these problems, they propose a Virtual Trial Room.

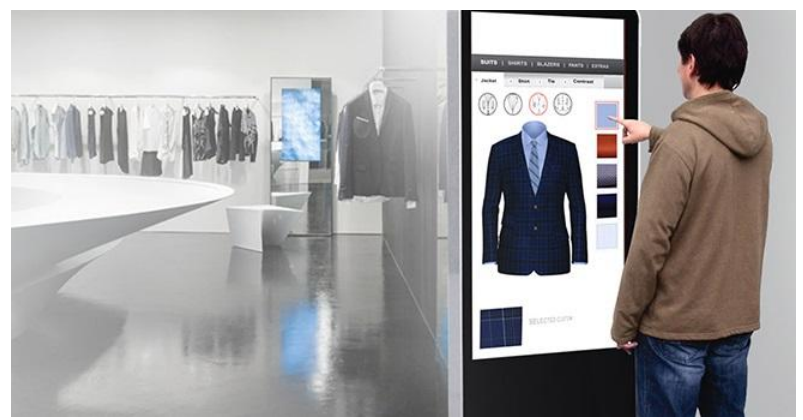

Fig 3: Garment Selection

\section{PROPOSED SYSTEM}

The Virtual mirror concept is applied through set of background and foreground images. User have to select dummy photograph available on web as per his/her choice with color ton or they can able to click picture from webcam or any portable device and check on that image. After selecting dummy photo, product image is selected which will merged in the mirror and it gives Augmented Reality experience to try and buy the readymade product. This Try-on facility is implemented for Top clothes only. Technically to achieve this Augmented Reality they implement client side scripting code using Javascript. As Js is the light-weight client side scripting and it also has numerous methods of properties which is going to help us to achieve their Proposed system. This proposed work has also some constraints as the product images must be edited with specified size and resolution as to compensate them inside mirror, so extra image sizing is required before uploading them into website. In this proposed system we are going to use standard sizes of the garment such as small, large, medium XL. People can choose from products and use TRY - ON facility for upper body like Tops, T-shirts, shirts etc. to check whether the product is suits them or not. Once they check this they get the idea to buy this product or not. User project contains the facility of buying multiple product via cart facility. User can also make online payment / COD (Cash On Delivery) for the order transaction. They will use free payment gateway for making online payment like pay pal etc. The proposed web portal has 3 different interfaces Admin, Customer, Visitor. Admin can manage and control all data \& users. He is the supper user of web portal. Customer can buy new products using TRY ON facility, check order history, post feedback etc. Visitor can only view the products $\&$ check feedback.

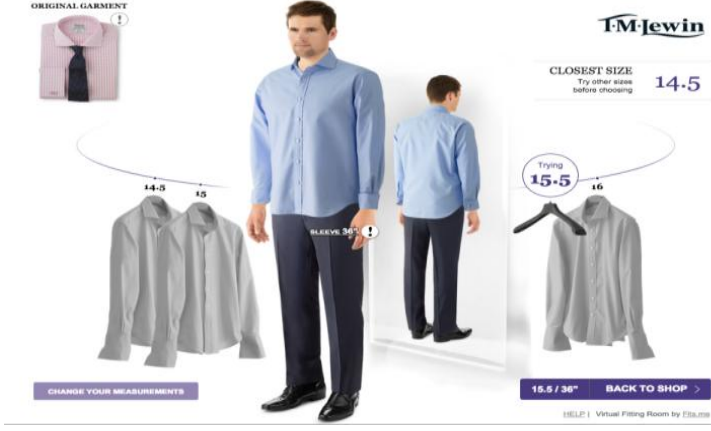

Fig 4: Static garment

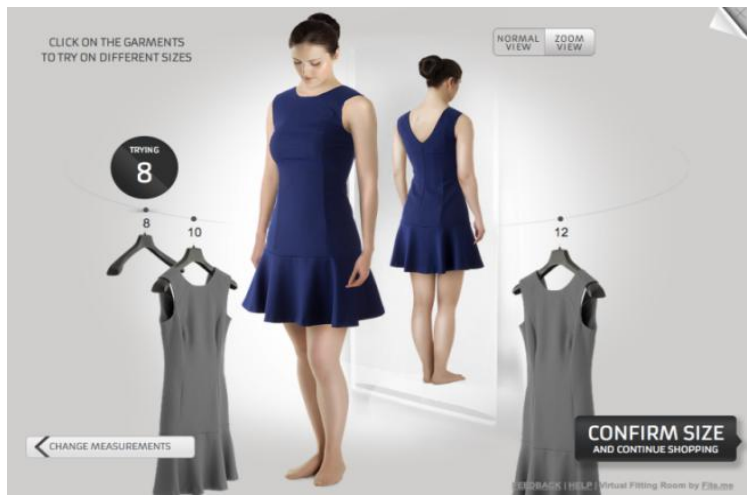

Fig 5: Garment Selection

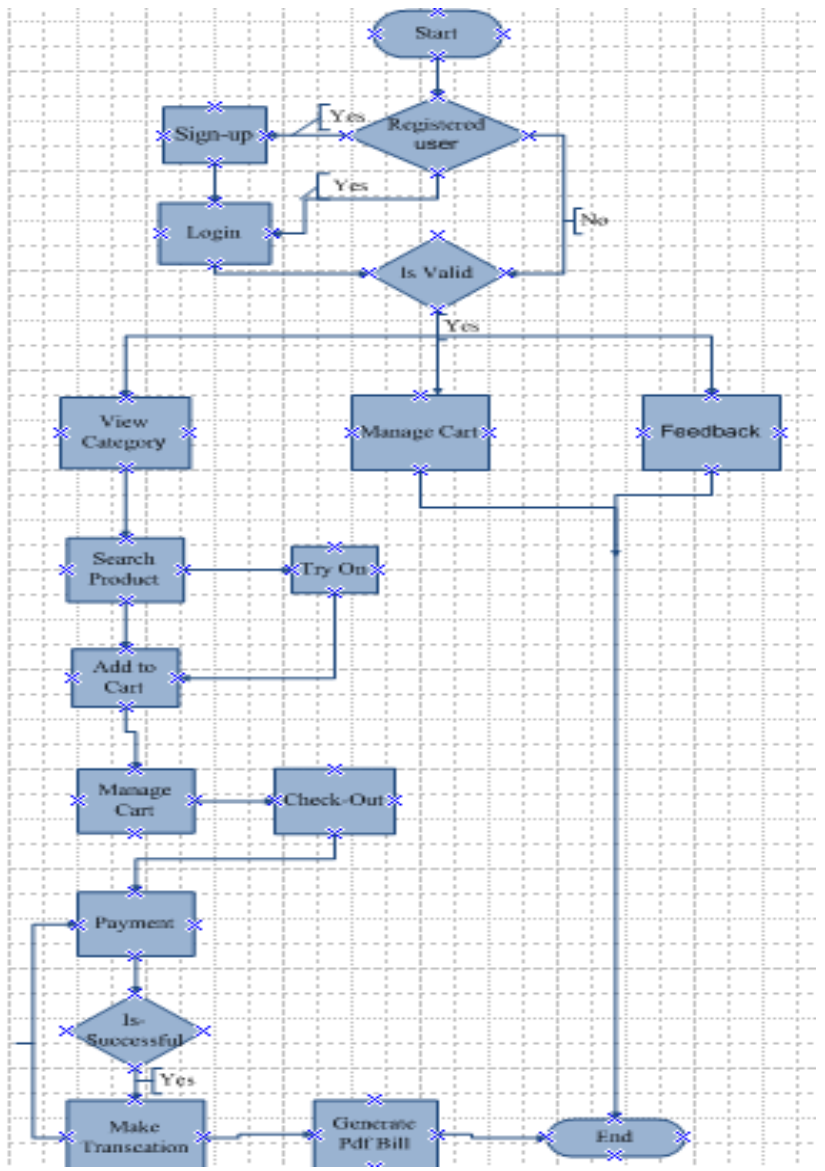

Fig 6: Flow-Chart of the System 


\section{CONCLUSION}

This report provide Augmented Reality experience to try and buy the readymade product. . People can choose from products and use TRY - ON facility for upper body like Tops, T-shirts, shirts etc. to check whether the product is suits them or not. Check order history, post feedback etc. Visitor can only view the products $\&$ check feedback.

\section{FUTURE WORK}

This report will provide unique feature of Virtualization mirror, in which customers can able to check whether that particular garment is suitable for them or not while purchasing. Most of the E-Commerce website support this module by implementing in it ; with the concept of Augmented reality. The system is an improvement to the existing system where the tracked user is able to try $2 \mathrm{D}$ clothes that include cloth simulation and can be viewed from different angles and react as real clothes.

\section{REFERENCES}

[1] Jaychand Upadhyay, Divya Shukla, Nidhi Patel, Sheetal Nangare"Virtual Trial Dressing" technology: International Journal of Innovative Research in Computer ISSN Online(2320-9801) Print (2320-9798)

[2] "Automatic modeling of virtual humans and body clothing", Nadia Magnenat-Thalmann, H. Seo, F. Cordier, Proc. 3-D Digital imaging and modeling, IEEE Computer Society Press 2003

[3] Mujahid, 2a et al. "Modeling Virtual Cloth to Display Realistic Shape and Force Based on Physical Data." Transactions of the Institute of Systems Control and Information Engineers 16.4 (2003)

[4] January 2011, Volume 51, Issue 1, pp 341-377|Cite as Augmented reality technologies, systems and applications 